\title{
Serologic Characterization of Leptospira among Rats Trapped in Selected Public Markets in Iloilo City, Philippines
}

\author{
Pia Regina Fatima C. Zamora ${ }^{1}$ and Nina G. Gloriani ${ }^{2}$ \\ ${ }^{1}$ College of Medicine, University of the Philippines Manila \\ ${ }^{2}$ Department of Medical Microbiology, College of Public Health, University of the Philippines Manila
}

\begin{abstract}
Objective. Rats have been identified as primary sources of leptospires in the environment. This study aimed to characterize Leptospira species circulating among rats found in public markets in Iloilo City, Philippines.

Methods. Dark-field microscopy was used to determine leptospire presence in tissue cultures. Isolates from the cultures were characterized via serotyping with monoclonal and polyclonal antibodies. To characterize the antibodies present in rat sera, the microscopic agglutination test (MAT) was used.

Results. In this study, 19 rats were obtained from 7 markets in Iloilo City. Three (3) rats (15.8\%) were found to harbor leptospires in the urinary bladder (2) and kidney (1). Serotyping of the isolates showed that they did not belong to previously reported common serovars in the Philippines such as Manilae, Losbanos, Javanica or Grippotyphosa. Using another panel of polyclonal antibodies, it was shown that the isolates belonged to serovar Icterohaemorrhagiae. The MAT results showed that 16 (84.2\%) serum samples were positive for anti-Leptospira antibodies. The most common infecting serovars were Autumnalis (47.4\%), Pomona (42.1\%), Copenhageni (36.8\%), and Hebdomadis (31.6\%). Other infecting serovars identified were Icterohaemorrhagiae, Poi, Grippotyphosa, Patoc, and Pyrogenes.
\end{abstract}

Conclusion. The results of the present study provide baseline data on the circulating leptospiral serovars in Iloilo City. Results suggest the possible role of rats in disease transmission in the study areas.

Key Words: Leptospirosis, Leptospira, MAT, Iloilo, public markets

\section{Introduction}

Leptospirosis is a zoonotic infection that occurs worldwide. There are more than 500,000 human cases reported annually. ${ }^{1}$ The disease exists with a higher incidence in tropical areas such as Latin America, India, and Southeast Asia. It is also present, but to a lesser extent, in temperate areas such as the European Union and Japan.

Corresponding author: Pia Regina Fatima C. Zamora

Post-Graduate Institute of Medicine

College of Medicine

University of the Philippines Manila

Taft Avenue, Ermita, Manila 1000 Philippines

Telephone: +632 5361319

Fax No.: +632 5260371

Email: upcmpgim@gmail.com
Although several studies have already been done to determine the extent of disease occurrence among populations, worldwide prevalence rates remain underestimated. This may be attributed to the disease being protean in nature. $^{2}$

Natural carriers of leptospires are rodents and domestic animals such as dogs, pigs, and cattle. Rodents, however, are considered to be the primary reservoir for leptospirosis and are primary channels through which the disease affects humans. ${ }^{3}$ Rodents, from which leptospires are usually isolated, are the common rats found in houses, sewers, dumpsites, markets and farmlands.

Disease transmission usually occurs through contact with environment (i.e. water or soil) contaminated by urine of infected animals. ${ }^{4}$ Kidney involvement in rats is chronic and usually does not cause disease. It results in the shedding of large numbers of leptospires in the urine which is cited as the main source of environmental contamination resulting in infection in humans. ${ }^{5}$

In the Philippines, the disease has a peak occurrence during or immediately following periods of high precipitation $^{6}$ during the rainy months from June to November. It is occupational in nature ${ }^{7}$ and affects primarily the male population especially those in the second, third, and fourth decades of life..$^{8,9,10}$ In a study done by Yanagihara et al, it was reported that $70 \%$ of 1200 suspected cases in the Philippines from 1998 to 2001, were serologically-positive. The case fatality rate was found to be $12-14 \%$ in 2 government hospitals. ${ }^{11}$

The province of Iloilo which is frequented by typhoons and subsequent flooding also had several confirmed and suspected cases. Yanagihara et al reported that morbidity in the rural area of Cabatuan, Iloilo, where majority of the residents are farmers, was estimated to be 147 cases per 100,000 populations. ${ }^{11}$ During the period of January-August 2011, there were 158 reported cases in the province with a case fatality rate of $8.23 \%$. Seventeen of these cases were from Iloilo City. ${ }^{12}$

Immunity against the disease is serovar-specific, ${ }^{13}$ thus, permanent immunity against the disease is less likely to occur, if not impossible. The diagnosis for the disease is also difficult because of numerous leptospiral serovars infecting humans and the non-specific signs and symptoms of 
leptospirosis. For better diagnosis and as aid for vaccine development in an area, the prevalent leptospiral serovars affecting humans and animal reservoirs must first be identified. ${ }^{5}$

There have been few publications reporting leptospirosis among rats in the Philippines. One study done by Villanueva et al reported that forty-six (46) out of 106 rats trapped in various places in Metro Manila and Laguna, Philippines harbored leptospires belonging to L. interrogans serovars Manilae and Losbanos, serogroup Grippotyphosa, and L. borgpetersenii serogroup Javanica. ${ }^{14}$ The study by Villanueva et al was done in Metro Manila and Laguna only. This study, therefore, aimed to isolate leptospires from blood, kidneys, urinary bladders, and urine samples of rats found in public markets in Iloilo City, Philippines. It also aimed to serologically characterize the isolated leptospires using monoclonal (mAbs) and polyclonal antibodies (pAbs). Lastly, it aimed to determine the seroprevalence rates and the prevailing Leptospira serovars in rats using the microscopic agglutination test (MAT).

\section{Methods}

This is a cross-sectional study wherein the population of rats that was used was conveniently sampled from the major public markets found in each of the 6 districts (Figure 1) of Iloilo City. The rats were trapped during the following periods: October 25 - November 4, 2011 and December 21 31, 2011.

Trapping of rats and sample collection. Rat traps were left in pre-determined locations inside the markets overnight. Ten (10) traps were set in each market for 3 consecutive days. Only the rats trapped within the time given were included in the study. The trapped rats were euthanized by means of carbon dioxide $\left(\mathrm{CO}_{2}\right)$ inhalation for 10 minutes. Whole blood, urine, urinary bladder, and kidney were aseptically collected for culture and serum for antibody testing. ${ }^{15,16}$ The disse ction of rats, collection of tissue and organ samples, and processing of the samples were done at the University of the Philippines Iloilo - Postgraduate Biology Laboratory.

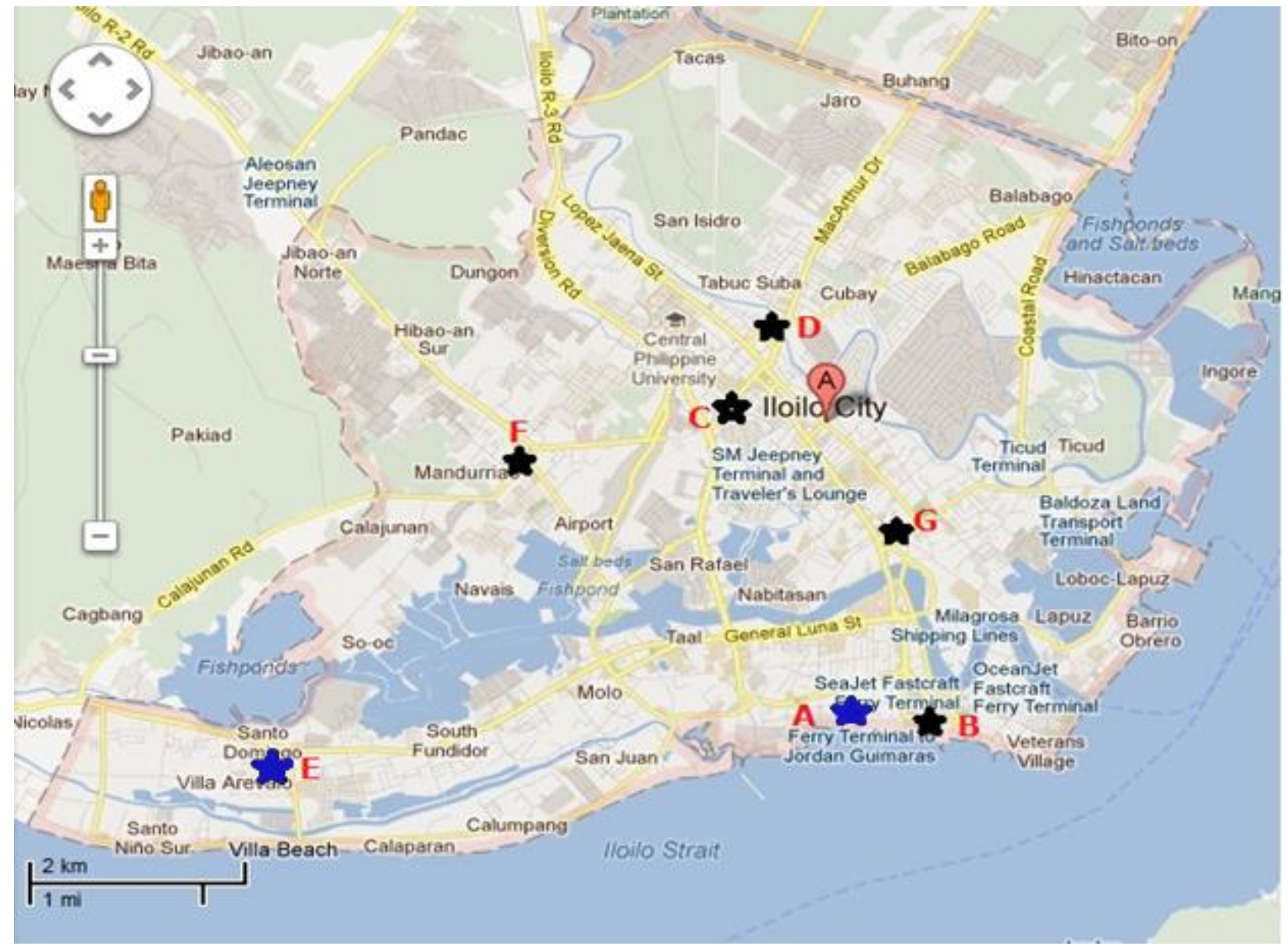

Figure 1. Map of public markets where rats were trapped. A. Central Public Market; B. Iloilo Terminal Market; C. Jaro Big Market; D. Jaro Small Market; E. Arevalo Public Market; F. Mandurriao Public Market; G. La Paz Public Market.

(Source: Google Maps https://www.google.com.ph/maps/place/Iloilo+City. Accessed March 23, 2010.)

*The blue stars correspond to the public markets in Iloilo City from which rats harbouring leptospires were trapped. 
Table 1. Serogroups, Serovars, and Strains of the Leptospira Antigens Used in MAT

\begin{tabular}{llll}
\hline & Serogroups & Serovars & Strains \\
\hline Leptospira & Pyrogenes & Manila & LT 398 \\
& Pyrogenes & Pyrogenes & Salinem \\
& Canicola & Canicola & Hond Utrecht \\
& Autumnalis & Autumnalis & IV \\
& Bataviae & Losbanos & Akiyami A \\
& Hebdomadis & Hebdomadis & LT 101-69 \\
& Australis & Australis & Akiyami B \\
& Icterohaemorrhagiae & Copenhageni & Akiyami C \\
& Icterohaemorrhagiae & Icterohaemorrhagiae & M20 \\
& Icterohaemorrhagiae & Icterohaemorrhagiae & RGA \\
& Pomona & Pomona & Ictero No. 1 \\
& Sejroe & Hardjo & Pomona \\
Grippotyphosa & Ratnapura & Hardjoprajitno \\
borgpetersenii & Javanica & Tarassovi & UP-BL-FR13 \\
Leptospira & Grippotyphosa & Gorepelitsin \\
kirschneri & & & Poi \\
Leptospira & Semaranga & Semaranga & Moskva V \\
meyeri & & & Seldrat \\
biflexa & Semaranga & Patoc & Patoc 1 \\
\hline
\end{tabular}

Processing of specimens and isolation of leptospires. Samples were collected and processed based on previous studies. ${ }^{14,15,16}$ Briefly, whole blood was centrifuged for $20 \mathrm{~min}$ at $3000 \mathrm{rpm}$, serum was collected and stored in a cryogenic vial at $-20^{\circ} \mathrm{C}$ until use. Urine was collected from the urinary bladder using a sterile syringe. When the urinary bladder was empty, the organ was cut and suspended in 5Fluorouracil-containing-Korthof's (5-FU-Korthof's) medium for 1 hour at $30^{\circ} \mathrm{C}$. Whole blood and urine samples were cultured in 3 tubes (per sample) containing $4 \mathrm{ml} 5$-FUKorthof's medium. The first tube contained 2 drops of the blood or urine, and the $2^{\text {nd }}$ and $3^{\text {rd }}$ tubes contained 3 drops each of the specimen. The kidneys were aseptically collected and macerated with a $2.5 \mathrm{ml}$ sterile syringe. The macerated kidney was suspended in 5-FU-Korthof's medium for 24 hours and incubated at $30^{\circ} \mathrm{C}$. From the initial suspensions of kidneys, $500 \mu \mathrm{l}$ of the supernatant was sub-cultured into fresh 5-FU-Korthof's medium.

All the cultures were incubated at $30^{\circ} \mathrm{C}$. They were examined for growth of leptospires weekly for 3 months using dark-field microscopy.

Serotyping of isolates. Serotyping of isolated leptospires was done using anti-serovar/serogroup specific mAbs and pAbs against 4 serovars, which were previously reported to be prevalent in the Philippines (i.e. serovars Manilae, Losbanos, Javanica, and Grippotyphosa). This was done based on the procedures used in MAT. ${ }^{14,15,16}$ If the serotyping results show that the isolates do not belong to any of the serovars mentioned, they will be sent to Kyushu University, Fukuoka, Japan for further analysis using another panel of mAbs and pAbs. Briefly, the isolate was mixed with the mAbs or pAbs in a 1:1 dilution. Wells with phosphate-buffered water were diluted in the same manner and were negative controls. After all the dilutions have been made, the plates were incubated at $30^{\circ} \mathrm{C}$ for $2-4$ hours. The agglutination of the leptospires with the antiserovar/serogroup-specific antibodies should be $\geq 90 \%$ compared to the negative control. If there were two or more reactions, quantitative MAT was done. In the quantitative MAT, the serovar that had the highest reaction (titer) was considered to be the probable serovar/serogroup of the isolate.

Microscopic Agglutination Test (MAT). The microscopic agglutination test aids in the detection of antibodies generated by an organism against an infecting serovar. In this study, rats' sera were each reacted with a panel of 18 live antigen suspensions of leptospiral serovars (Table 1). After incubation, the serum-antigen mixtures were examined for agglutination, and the corresponding titers were determined. ${ }^{17}$ The details of the procedure done in this study were based on the methods previously reported. ${ }^{14,15,16}$ Both qualitative and quantitative MAT were done at the UP Manila College of Public Health - Leptospirosis Prevention and Control (LEPCON) Laboratory. A qualitative MAT was used to screen for the specificity of antibodies present in the sera of rats. After screening, quantitative MAT was used to determine the titers of the antibodies present in the sera. The dilution (serum and antigen) giving a $50 \%$ or more agglutination at $\geq 1: 20$ titer is considered to be the endpoint titer (MAT-positive; significant titer).

Animal Ethics. All procedures involving rats were reviewed and approved by the Institutional Animal Care and Use Committee (IACUC) and the University of the Philippines Manila - Research and Ethics Board (UPM-REB).

\section{Results}

A total of 19 rats were caught in the seven markets included in the study (Table 2). Of the 19 rats, $10(52.6 \%)$ were males and $9(47.4 \%)$ were females. Most of the trapped rats were from Iloilo Terminal Market (5) and Jaro Big Market (5).

Table 2. Number and Percentage of Rats trapped per Market

\begin{tabular}{|c|c|}
\hline Market Sources & \# of rats $(\%)$ \\
\hline A (Central Public Market) & $2(10.5 \%)$ \\
\hline B (Iloilo Terminal Market) & $5(26.3 \%)$ \\
\hline C (Jaro Big Market) & $5(26.3 \%)$ \\
\hline D (Jaro Small Market) & $1(5.3 \%)$ \\
\hline E (Arevalo Public Market) & $3(15.8 \%)$ \\
\hline F (Mandurriao Public Market) & $1(5.3 \%)$ \\
\hline G (La Paz Public Market) & $2(10.5 \%)$ \\
\hline Total & $19(100 \%)$ \\
\hline
\end{tabular}

Culture results showed that 3 rats $(15.8 \%)$ harbored leptospires. Two rats from Arevalo Public Market had leptospires in their urinary bladder. One rat caught in Central Public Market had leptospires in the kidney. However, the investigator failed to obtain pure culture of leptospires from the latter due to bacterial contamination. 
Serotyping of the 2 isolates from Central Public Market showed that they did not belong to serovars Manilae, Losbanos, Javanica or Grippotyphosa. The serotyping done at Kyushu Univeristy revealed that both isolates belonged to serovar Icterohaemorrhagiae.

Antibodies against leptospires were detected in 16 out of $19(84.2 \%)$ rat serum samples analyzed. Of the 16 serum samples, $11(68.8 \%)$ had anti-Leptospira antibodies against multiple serovars (Table 3). A positive agglutination reaction was observed in 10 out of 18 leptospiral antigens used in this study (Table 4). Based on MAT results, the predominant infecting serovars in rats were Autumnalis $(9 / 19 ; 47.4 \%)$, Pomona $(8 / 19 ; 42.1 \%)$, Copenhageni $(7 / 19 ;$ $36.8 \%)$, and Hebdomadis $(6 / 19 ; 31.6 \%)$. On the other hand, the least number of positive serologic reactions was observed in serovar Pyrogenes (1/19, 5.3\%).

The reciprocal agglutination titers for serum samples varied from 20 to 20,480. The antibody titer with the highest number of positive serologic reactions was 20 (52.6\%). On the other hand, the antibody titers with the least number of positive serologic reactions were 1,280; 5,120; and 20,480.

Table 3. Distribution of Rat Sera According to the Number and Percentage of Infecting Serovars Identified

\begin{tabular}{cc}
\hline $\begin{array}{c}\text { Number of sera with positive } \\
\text { MAT results }\end{array}$ & $\begin{array}{c}\text { Number of serovars that reacted per } \\
\text { positive sample (\%) }\end{array}$ \\
\hline $\mathbf{0}$ & $3(15.8 \%)$ \\
$\mathbf{1}$ & $5(26.3 \%)$ \\
$\mathbf{2}$ & $5(26.3 \%)$ \\
$\mathbf{3}$ & $3(15.8 \%)$ \\
$\mathbf{4}$ & $1(5.3 \%)$ \\
$\mathbf{5}$ & $1(5.3 \%)$ \\
$\mathbf{6}$ & $1(5.3 \%)$ \\
Total & $19(100 \%)$ \\
\hline
\end{tabular}

\section{Discussion}

Serological characterization of the 2 isolates showed that they belong to serovar Icterohaemorrhagiae. The identified serovar is different from previously reported prevalent serovars/serogroups by Villanueva et $\mathrm{al}^{14}$ (Manilae, Losbanos, Javanica or Grippotyphosa) and Gloriani et al ${ }^{18}$
(Manilae, Javanica or Grippotyphosa). This supports previously established knowledge that existing serovars may differ from one area to another.

Agglutination reactions done in this study showed that $84.2 \%$ of the serum samples analyzed had antibodies against leptospires. Of the serum samples that tested positive for antibodies, $68.8 \%$ had anti-Leptospira antibodies against multiple serovars. The predominant infecting serovars were Autumnalis, Pomona, Copenhageni, and Hebdomadis. A study done by Villanueva et $\mathrm{al}^{14}$ on rats collected within Metro Manila and Laguna showed that $92 \%$ of the serum samples were positive for anti-Leptospira antibodies with the most common infecting serovars being Manilae, Hebdomadis, and Losbanos. There is, however, a more recent study done in 2010-2012 which reported the predominance of Copenhageni, Poi, and Grippotyphosa among rats gathered from NCR and Nueva Ecija province. ${ }^{18}$ The same infecting serovars were identified among rats in this study with serovar Copenhageni being one of the predominant serovars. Other serovars which were identified in both studies were Icterohemorrhagiae and Pyrogenes. Aside from the infecting serovars identified, it is possible that there are serovars that were not accurately identified because of the cross-reactivity of the saprophytic L. biflexa serovar Patoc (strain Patoc 1). ${ }^{15}$ Thus, there is a possibility that there may be some serovars that may have caused infections in the rats but were not included in the panel of antigens used for MAT.

It must be noted that antibodies against multiple serovars have been detected in most serum samples. This provides possible evidence that multiple infection of similar and different time frames can occur in rats. Varying antibody titers against a particular serovar have also been observed in the rat samples. A significant number of agglutinated leptospires elicited by a serum sample with 1:20 dilution means that the rat has a low antibody titer against that particular serovar, signifying a past infection. Serum samples generating agglutination reactions with $1: 1,280,1: 5,120$, and 1:20,480 dilutions signify a more recent infection or an anamnestic immune reaction in rats. ${ }^{19}$

Table 4. Number and Percentage of Rats According to Infecting Serovars Identified and the Corresponding Antibody Titres

\begin{tabular}{|c|c|c|c|c|c|c|c|c|c|c|}
\hline \multirow[b]{2}{*}{$\underline{\text { Serovars }}$} & \multicolumn{10}{|c|}{ Antibody titers } \\
\hline & 20 & 40 & 80 & 160 & 320 & 640 & 1280 & 5120 & 20480 & $\begin{array}{c}\text { Number of rats } \\
\text { positive for Abs/19 (\%) }\end{array}$ \\
\hline Autumnalis & 1 & 2 & 2 & 3 & 0 & 0 & 1 & 0 & 0 & $9(47.4 \%)$ \\
\hline Pomona & 0 & 1 & 2 & 0 & 3 & 2 & 0 & 0 & 0 & $8(42.1 \%)$ \\
\hline Copenhageni & 1 & 0 & 2 & 1 & 2 & 0 & 0 & 0 & 1 & $7(36.8 \%)$ \\
\hline Hebdomadis & 4 & 1 & 0 & 0 & 0 & 1 & 0 & 0 & 0 & $6(31.6 \%)$ \\
\hline Icterohaemorrhagiae & 0 & 0 & 1 & 0 & 0 & 1 & 0 & 1 & 0 & $3(15.8 \%)$ \\
\hline Poi & 2 & 0 & 0 & 0 & 0 & 0 & 0 & 0 & 0 & $2(10.5 \%)$ \\
\hline Grippotyphosa & 1 & 1 & 0 & 0 & 0 & 0 & 0 & 0 & 0 & $2(10.5 \%)$ \\
\hline Patoc & 1 & 1 & 0 & 0 & 0 & 0 & 0 & 0 & 0 & $2(10.5 \%)$ \\
\hline Pyrogenes & 0 & 0 & 0 & 1 & 0 & 0 & 0 & 0 & 0 & $1(5.3 \%)$ \\
\hline $\begin{array}{c}\text { Number of rats } \\
\text { positive for Abs/19 (\%) }\end{array}$ & $\begin{array}{c}10 \\
(52.6 \%)\end{array}$ & $\begin{array}{c}6 \\
(31.6 \%)\end{array}$ & $\begin{array}{c}7 \\
(36.8 \%)\end{array}$ & $\begin{array}{c}5 \\
(26.3 \%) \\
\end{array}$ & $\begin{array}{c}5 \\
(26.3 \%)\end{array}$ & $\begin{array}{c}4 \\
(21.1 \%)\end{array}$ & $\begin{array}{c}1 \\
(5.3 \%) \\
\end{array}$ & $\begin{array}{c}1 \\
(5.3 \%)\end{array}$ & $\begin{array}{c}1 \\
(5.3 \%) \\
\end{array}$ & -- \\
\hline
\end{tabular}


The above results show that rats are important reservoirs of pathogenic leptospires. In the current study, 3 rats were found to harbor these organisms. The rat collection for this study had a lower yield compared to studies done by Villanueva et $\mathrm{al}^{14}$ and Gloriani et al. ${ }^{18}$ The collection for the two studies had a yield of 106 rats and 51 rats, respectively. The low yield of rat collection in this study may be attributed to limited areas for sampling, low rat density in the areas sampled, and different bait preference of rats. The limited time allotted for rat collection and the occasional rainy weather during the conduct of the study may also be factors for the low yield of rats in this study. ${ }^{18,20}$

\section{Conclusions}

The results of the present study provide baseline data on the circulating leptospiral serovars in Iloilo City. It also shows that the infecting serovars may differ from one area to another. Furthermore, the results suggest the possible role of rats in disease transmission in the study areas.

Such information can be used to update the antigens used in serologic characterization and thus, improve the accuracy and reliability of serologic tests for leptospirosis. Furthermore, the Leptospira serovars identified in this study, together with those from previous studies, can be used to determine vaccine candidates and eventually develop an effective vaccine against this infectious disease in the Philippine setting.

\section{Recommendations}

This is a preliminary study on prevalent Leptospira serovars among rats found in markets in Iloilo City. Due to financial and time constraints, the conduct of the study was limited to the small number of rats trapped only in selected locations in the city. For a more comprehensive study, it is recommended that all markets in Iloilo City be set as locations from which rats can be collected. The presence of different serovars of leptospires in water-filled areas such as farms or rice paddies should also be investigated. The schedule of trapping should also be distributed all throughout the year to see the association between circulating serovars in the area and the weather condition at the time of trapping. It is also recommended that an association study be conducted on the circulating serovars among rodents and domestic animals, and the serovars present in human cases. The study may be conducted in areas where outbreaks or cases have been reported.

The results of this study stress the need for the national government and all the local government units of the country to implement effective preventive and control measures against the disease. As evidenced by the results of this study, the role of rats in disease transmission is a promising target. The potential of massive rat control in the form of chemical or mechanical means may be investigated and, if found to be effective and safe, may then be implemented. Other issues such as rapid urbanization, poor infrastructures, deforestation, and lack of compulsory cooperation to practice proper waste disposal must also be addressed in order for preventive and control measures to be effective. ${ }^{12,} 21$

\section{Acknowledgments}

The investigators are grateful to Ms. Rubelia Baterna, Ms. Kriselda Rivera, Ms. Crystal Amiel Estrada, and Dr. Sharon Y. A. M. Villanueva, for their guidance and support during the conduct of this study. They are also grateful to the University of the Philippines Iloilo - Postgraduate Biology Laboratory and UP Manila College of Public Health LEPCON Laboratory for permitting the use of their facilities, and the DOST-PCHRD for funding this study.

\section{References}

1. World Health Organization. Informal Consultation on Global Burden of Leptospirosis: Methods of Assessment. Geneva: 2006 October.

2. Victoriano AFB, Smythe LD, Gloriani-Barzaga N, et al. Leptospirosis in the Asia Pacific Region. BMC Infect Dis. 2009; 9:147.

3. Kingscote BF. Leptospirosis: An occupational hazard to veterinarians. Can Vet J. 1986; 27(2):78-81.

4. Michel V, Branger C, Andre-Fontaine G. Epidemiology of leptospirosis. Rev Cubana Med Trop. 2002; 54(1):7-10.

5. Dworkin M, Falkow S, Rosenberg E, Schleifer KH, Stackebrandt E. Prokaryotes: A Handbook on the Biology of Bacteria. Springer Science+Business Media. New York: USA; 2006.

6. Orpilla-Bautista ICL, Panaligan MM. Predictors of mortality among patients with leptospirosis admitted at the JRRMMC. Phil J Microbiol Infect Dis. 2002; 31(4):145-9.

7. Yang CW, Pan MJ, Wu MS, et al. Leptospirosis: an ignored cause of acute renal failure in Taiwan. Am J Kidney Dis. 1997; 30(6):840-5.

8. Villela G, Edmilao MI, Cordero CP, Valdez JR, UP-PGH Leptospirosis Study Group. Predictors of oliguria and complications/mortality among patients with acute renal failure due to leptospirosis - A PGH Experience. Phillip J Intern Med. 2000; 38(5):235-42.

9. Casiple LC. Thrombocytopenia and bleeding in leptospirosis. Phil J Microbiol Infect Dis. 1998; 27:18-22.

10. Flor BJA, Edmilao MIE, Lim AV, et al. Clinical and diagnostic features in leptospirosis-induced myocarditis. Philipp J Cardiol. 1997; 25(1):27-32.

11. Yanagihara Y, Villanueva SYAM, Yoshida S, Okamoto Y, Masuzawa T. Current status of Leptospirosis in Japan and Philippines. Comparative Immunology, Microbiology and Infectious Diseases. 2007; 30:399-413.

12. GMA News Online. DOH alarmed over 290 leptospirosis cases, 29 deaths in Western Visayas [Online]. 2011 [cited 2012 Aug]. Available from http://www.gmanetwork.com/news/story/230355/news/regions/ doh-alarmed-over-290-leptospirosis-cases-29-deaths-in-wvisayas.

13. Brooks GF, Carroll KC, Butel JS, Morse SA. Jawetz, Melnick, and Adelberg's Medical Microbiology, 24 $4^{\text {th }}$ ed. USA: The McGraw-Hill Companies, Inc.; 2007. pp 339-341.

14. Villanueva SY, Ezoe H, Baterna RA, et al. Serologic and molecular studies of Leptospira and leptospirosis among rats in the Philippines. Am J Trop Med Hyg. 2010; 82(5):889-98.

15. World Health Organization. Leptospirosis Laboratory Manual. 2007.

16. World Health Organization, International Leptospirosis Society. Human Leptospirosis: Guidance for Diagnosis, Surveillance and Control. 2003.

17. Levett PN. Leptospirosis. Clin Microbiol Rev. 2001;14(2): 296-326.

18. Gloriani N. Identification of Prevalent Leptospira Serovars in the Philippines (2010-2012). Unpublished.

19. Faine S, Adler B, Bolin C, Perolat P. Leptospira and Leptospirosis, $2^{\text {nd }}$ ed. Melbourne: MediSci. 1999.

20. Key J. Guidelines for Urban Rat Control. Pacific Invasives Learning Network (PILN). 2008.

21. Easton A. Leptospirosis in Philippine floods. BMJ. 1999;319(7204):212. 